\title{
FORMAÇÃO INICIAL DE PROFESSORES: DESAFIOS E POSSIBILIDADES PARA INCORPORAÇÃO DE TECNOLOGIAS DIGITAIS DE INFORMAÇÃO E COMUNICAÇÃO.
}

\author{
Daniele dos Santos Martins Vieira, Renata Portela Rinaldi \\ Universidade Estadual Paulista - UNESP, Curso de Pedagogia, Presidente Prudente, SP. E-mail: \\ danielemartins1903@hotmail.com.
}

\begin{abstract}
RESUMO
O texto apresenta o relato de experiência e os resultados do trabalho realizado na disciplina de Tecnologias Aplicadas à Educação no curso de licenciatura em Pedagogia em uma universidade pública no interior do estado de São Paulo. Visa apresentar possibilidades e desafios do processo de incorporação de tecnologias digitais de informação e comunicação (TDIC) na formação inicial de futuros professores que atuarão na educação infantil e no ensino fundamental. Pautamo-nos no método descritivo-analítico e os dados foram obtidos com as atividades realizadas em sala de aula com recursos off-line e on-line. Os resultados apontam que o papel do professor e as estratégias didáticas para trabalhar conteúdos e recursos de TDIC na formação inicial precisam ser ressignificados desafiando os futuros professores a investir em formas diversificadas de construção do conhecimento. Acreditamos que assim, aprenderão a usar recursos de TDIC e poderão aprender a ensinar com elas consciente de suas possibilidades, mas também dos desafios para o ensino.
\end{abstract}

Palavras-chave: Formação inicial de professores, tecnologias digitais de informação e comunicação, ensino fundamental, educação infantil.

\section{INITIAL FORMATION OF PROFESSORS: CHALLENGES AND POSSIBILITIES FOR INCORPORATION OF DIGITAL TECHNOLOGIES OF INFORMATION AND COMMUNICATION.}

\begin{abstract}
The text present the report of experience and the results of realized work on discipline of Technology Applied in Education in the graduation to Pedagogy course at a public university on interior of the state of São Paulo. Aims to present possibilities and challenges in the process of incorporation of Digital Technologies of Information and Communication (DTIC) at the initial formation future professor that going to act in child education and fundamental education. We follow the analytical-descriptive method and the data was obtained by activities realized at classroom with offline and online resourses. The results show that the professor's paper and the didactics strategies for work of contents and resourses of DTIC in initial formation need to be resignified, challenging the future professor investing in diversified forms of construction the knowledge. We believe that like this, will learn to use the DTIC and will can learn to teach with them conscious the your possibilities, but also of challenges to the teaching.

Keywords: Initial formation of professor, digital Technologies of information and communication, basic education, child education.
\end{abstract}




\section{INTRODUÇÃO}

A atualidade tem sido marcada por grandes e constantes mudanças na área de mídias. Especificamente, as tecnologias digitais de informação e comunicação (TDIC) têm influenciado nossas vidas em todos os sentidos, ou seja, na forma como nos relacionamos, consumimos, comunicamos etc. Sendo de suma importância o seu uso, tendo como contribuinte desse grande progresso a internet (rede mundial de computadores), que diminuiu as barreiras de tempo e espaço nesse mundo globalizado e o tornou cada vez mais conectado. Em conformidade ao assunto Hack e Negri (2010) afirmam que a internet se tornou um modo prático para a comunicação e o compartilhamento de informações.

Ainda nessa direção Baladeli, Barros e Altoé (2012, p. 156-157) afirmam que:

[...] a adequação da educação às novas tendências trazidas pela sociedade da informação e do conhecimento, bem como a formação e o papel do professor do século XXI, também tendem a serem postos à prova, isso porque, no presente contexto, a informação e o conhecimento ganham destaque tanto político quanto socialmente. Em função da abertura comercial da Internet (rede mundial de computadores) em 1995, a produção, o armazenamento e a divulgação de informação ganham novos espaços.

Diante dessa realidade a incorporação da TDIC na educação se faz necessária, pois ela pode auxiliar o professor no processo de ensino e aprendizagem, como um recurso didático mais dinâmico, conhecido pelos estudantese que possibilita a eles a experimentação, por exemplo, a partir de simulação ou jogos, e a construção de conhecimentos de modo mais significativo. Mas, o problema é que nem sempre a escola e seus professores se apropriam do conhecimento de recursos de TDIC para ensinar conteúdos escolares 'com' e 'a partir' deles. Em alguns casos, utiliza o recurso sem qualquer alteração no planejamento didático e sem uma clara intencionalidade de sua incorporação no processo de ensino.

Atuar na formação inicial de professores incorporando conteúdos e recursos de TDIC, incentivando os futuros profissionais na apropriação desses recursos para desenvolver um trabalho pedagógico com objetivo de ensinar conteúdos escolares, pode se converter em uma experiência promissora para alteração do cenário atual de incorporação e utilização de TDIC no ensino nas escolas, especialmente das redes públicas.

Nessa perspectiva, o Projeto Político Pedagógico do curso de licenciatura em Pedagogia da Universidade Estadual Paulista "Júlio de Mesquita Filho" /Campus de Presidente Prudente, do ano de 2015, apresentou como um de seus objetivos: "Incentivar a produção e difusão de conhecimento científico-tecnológico docampo educacional, em contextos escolares e nãoescolares." (PROJETO POLÍTICO PEDAGÓGICO, 2015, p. 11). Sendo assim, é oferecida a disciplina Tecnologias Aplicadas à Educação, no quarto semestre do curso, voltada especificamente para o trabalho com conteúdos e recursos midiáticos e de TDIC.

Dessa forma, objetivamos com o presente texto descrever um relato de experiência, a partir do trabalho didático realizado com estudantes do 20 ano do curso de licenciatura em Pedagogia, no intuito de apresentarpossibilidades e desafios do processo de incorporação de tecnologias digitais de informação e comunicação (TDIC) na formação inicial de futuros professores que atuarão na educação infantil e no ensino fundamental, a partir da experiência de uma futura professora. 


\section{METODOLOGIA}

O presente texto enquadra-se como um relato de experiência pautado numa perspectiva descritivo-analítica. Esse procedimento tem como finalidade descrever o processo da experiência e discuti-la cotejando-a ao referencial teórico que fundamenta as produções sobre o tema. A disciplina foi planejada e desenvolvida a partir de uma perspectiva pedagógicadefinida como Aula Invertida (FlippedClassroom) (TUCKER, 2012).

Em um primeiro momento buscou conhecer as concepções que os futuros professores tinham sobre TDIC, Cibercultura, trabalho com TDIC no ensino, bem como concebiam possibilidades para o uso de TDIC na escola e na sala de aula. Após, foi entregue o plano de ensino e discutido cada elemento dele, bem como a abordagem pedagógica que orientaria nossas ações ao longo do tempo. Em um segundo momento, orientada pela proposta da abordagem pedagógica da Aula Invertidaa disciplina foi desenvolvida por meio de desafios propostos aos estudantes, a partir da fundamentação teórica sobre o tema e apresentação de recursos de tecnologias digitais de informação e comunicação (off-line e on-line) que tinha como principal objetivo mobilizar os futuros professores para aprendizagem e operação de diversos recursos de TDIC e, posteriormente, levá-los a, a partir do conhecimento construído sobre a incorporação de recursos de TDIC no ensino, planejar e construir um recurso de TDIC para o ensino de conteúdos escolares na educação infantil ou nos anos iniciais do ensino fundamental.

Para a produção em tela, analisaremos os resultados da experiência vivenciada pela estudante em dois desafios e a partir da construção de seu recurso pedagógico.

\section{RESULTADOS E DISCUSSÃO}

\section{NÃO ERA TÃO FÁCIL QUANTO PENSAMOS...}

Antes de iniciar as aulas da disciplina Tecnologias Aplicadas à Educação, o pensamento era de que sabia o necessário, mas com o primeiro desafio proposto pela professora, as primeiras dificuldades apareceram. Tínhamos a orientação prévia de leitura de dois textos que versavamsobreo histórico das tecnologiasdigitais de informação e comunicação e o conceito de ciberespaço. A turma foi organizada em grupos de cinco alunos que trabalhariam coletivamente durante a disciplina. O primeiro desafio consistiu em representar os conceitosdos textos de referência, suas características e evolução por meio de um recurso visual, no caso infográfico, com recursos on-line e off-line.

Etimologicamente a palavra infográfico significa Info (informação) +gráfico (desenho, imagem, representação visual). Ou seja, é um desenho (ou imagem) que com o auxílio de um texto, explica ou informa sobre um assunto. É uma estratégia para apresentar informações de forma visual e de fácil compreensão muito utilizada em jornais, tutoriais, manuais educativos etc.

Para a turma, além da compreensão da literatura que tratava do tema houve a necessidade de aprender a fazer o infográfico off-line e on-line. Para dar conta com sucesso do desafio utilizando o recursoon-line tivemos que aprender a manusear as ferramentas de algunssitescom distribuição de conteúdo gratuito sugeridos pela professora, conforme Quadro 1:

Quadro 1. Sugestões de sites para construção gratuita de infográfico.

\begin{tabular}{|l|l|}
\hline \multicolumn{1}{|c|}{ IDENTIFICAÇÃO } & \multicolumn{1}{c|}{ ENDEREÇO ELETRÔNICO } \\
\hline Venngage & https://venngage.com/ \\
\hline Visme & https://www.visme.co/ \\
\hline Genial. ly & https://www.genial.ly/pt-br?gclid=CIGq4cGOsdACFckGkQodaCAK-w \\
\hline Canva & https://www.canva.com/ \\
\hline
\end{tabular}

Fonte: Sistematizado pelas autoras a partir do plano de ensino da disciplina. 
Primeira grande dificuldade, alguns dos sitesestavam em inglês; em suma um desafio com vários empecilhos, como a apropriação e compreensão da fundamentação teórica, planejamento sobre a melhor forma de representá-lautilizando TDIC, por meio do recurso visual infográfico, aprender a manusear as ferramentas dos sites selecionados para a atividade. Com todas as dificuldades o desafio foi cumprido, o grupo explorou os sitessugeridos e também diferentes ferramentas off-line do pacote Windows (Power Point, Word e Paint) que permitiria concluir a tarefa proposta. As figuras 1 e 2 , respectivamente, apresentam o resultado desse trabalho.

Figura 1: Infográfico construído com recurso on-line

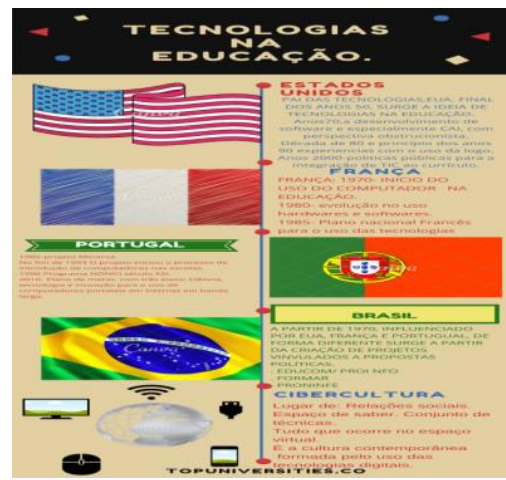

Fonte: Trabalho da disciplina, 2016.
Figura 2: Infográfico construído com recurso off-line

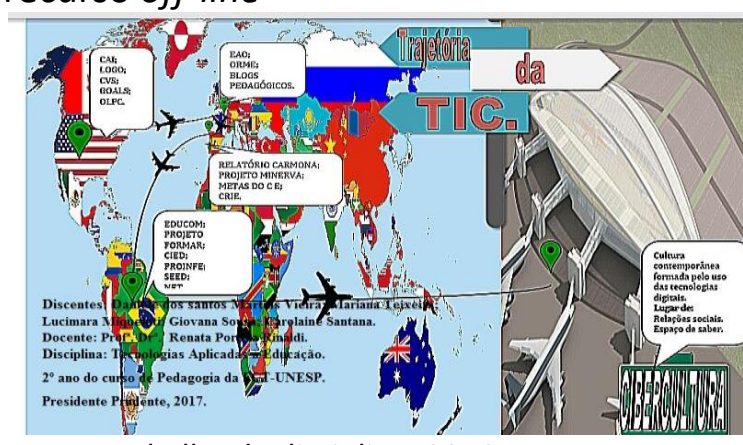

Fonte: Trabalho da disciplina, 2016.

Após a conclusão da atividade os grupos fizeram a apresentação do resultado e explicaçãodo conteúdo utilizando como recurso didático o infográfico, primeiramente construído on-line e depois off-line. A proposta para se trabalhar com essas duas perspectivas tem intuito evidenciar aos licenciandos que independente do conteúdo é possível explorar possibilidades tanto por meio da rede mundial de computadores quanto dos recursos de hardware e software que todo computador tem. Isto porque, é muito comum nas escolas públicas a existência de laboratórios de informática, entretanto, o funcionamento da internet nem sempre é uma realidade.

A avaliação da atividade pelos estudantes focou-se fundamentalmente na dificuldade de construção do recurso, primeiramente em ter a clareza de como construí-lo e da necessidade de planejamento para sua execução, pois a compreensão do conteúdo deveria estar expressa mais a partir das imagens do que de texto; segundo pela dificuldade com o idioma estrangeiro para manusear os sites on-line; por fim, da facilidade de se trabalhar com os recursos off-line.

A cada aula um novo desafio, a professora servia de mediadora no processo de realização das atividades. Os autores Hack e Negri (2010, p. 93) afirmam que "o professor é o agente organizador, dinamizador e orientador da construção do conhecimento através do auxílio crítico e criativo na seleção das inúmeras informações às quais o aluno é submetido cotidianamente."

Outra proposta de desafio colocada pela professora foi a partir das abordagens pedagógicas instrucionista e construcionista (ALMEIDA, 2001), que fundamentaram a incorporação de recursos de tecnologias de informação e comunicação na educação e no ensino, identificar recursos on-line, analisá-los e caracterizá-los segundo a abordagem e indicar o seu potencial para o ensino de crianças da educação infantil ou anos iniciais do ensino fundamental.

Nesse contexto, a abordagem instrucionistapode ser definida como:

[...] aquela em que o computador passa a exercer a função de transmissor da informação ao aluno por meio de um programa (software), ou seja, ele cumpre um papel semelhante ao de um professor que passa as informações. Estes softwares são sistemas nos quais o aluno interage 
diretamente com o computador, que é programado para apresentar o material instrutivo e verificar, por meio de testes, o que ele realmente assimilou. Nessa abordagem, o computador "ensina" o aluno, como ocorre nos métodos tradicionais de ensino ou método instrucionista. (RINALDI, 2008, p.381)

Ainda, segundo Rinaldi (2008) na abordagem construcionista o computador tem o papel de resolver problemas, o aluno recebe o papel de usuário, por meio da máquina é possível explicitar idéias e aprender por meio de softwares.

As abordagens foram trabalhadas com o objetivo de mostrar aosfuturos professores, como é possível escolher o recurso para ensinar conteúdos escolares, ter clareza da abordagem pedagógica que subsidiou sua construção, mas identificar a partir da sua exploração e usabilidade o potencial do recurso tecnológico no processo de ensino, a fim de respeitar as necessidades e potencializar a aprendizagemdos alunos. Como resultado do desafio proposto obteve-se o seguinte resultado (Figuras3 e 4).

Figura 4. Recurso on-

lineconstrucionista.

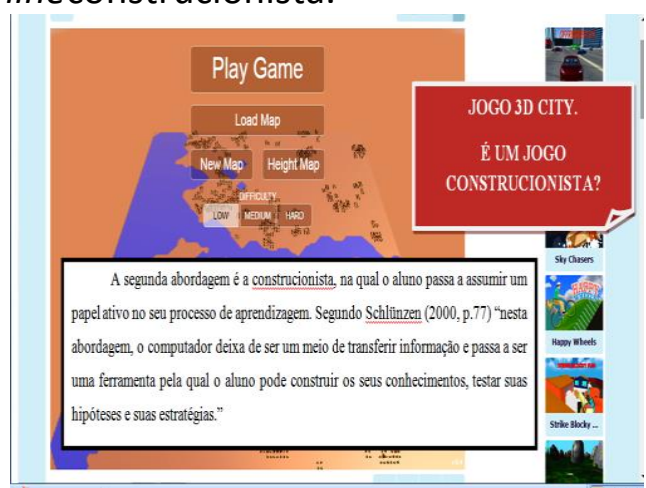

Disponível em:

http://www.escolagames.com.br/jogos/casa Magica/

Fonte: Trabalho da disciplina, 2016.
Figura 3. Recurso on-lineinstrucionista.

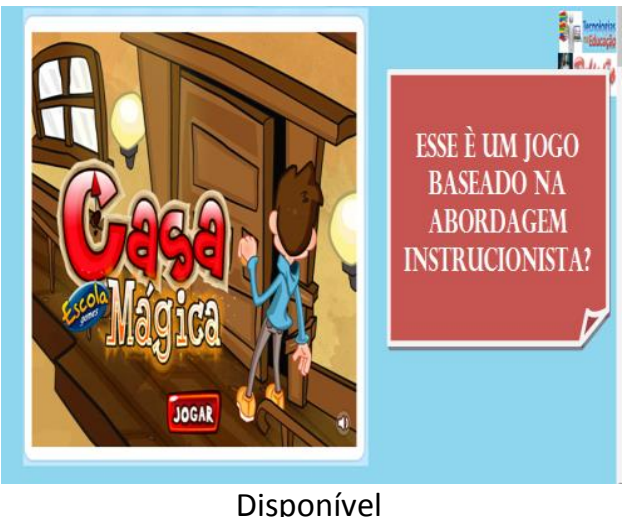

em:http://www.escolagames.com.br/jogos/casaMag ica/

Fonte: Trabalho da disciplina, 2016.

Na figura 3 o jogo "Casa Mágica" é um recurso instrucionista, pois os conteúdos trabalhados são previamente definidos pelo autor, organizados do nível mais simples para o mais complexo, com uma única resposta correta (instrução programada), no entanto, em caso de erro o jogador recebe um reforço, mas deve refazer a mesma etapa eapenas avançará quando fizer tudo corretamente como programado. Na figura 4, a ação do jogador não é direcionada, ao contrário ele é autor da ação e o computador executa as tarefas solicitadas. O jogo fornece diversas ferramentas para construir e reconstruir o que propicia uma interação constante entre sujeito e recurso. Nessa perspectiva o jogador ensinar o computador através de um software usado para resolver uma situação problema ou implementar um projeto. Nesse sentido, possibilita ao estudante a construção e desenvolvimento de novas e mais complexas estruturas mentais.

Por fim, após a compreensão da evolução da trajetória das TDIC à Cibercultura e sua incorporação na educação, como desafio final da disciplina foi proposta a criação de um recurso de TDIC para trabalhar conteúdos escolares para o ensino na educação infantil e anos iniciais do ensino fundamental. A proposta realizada pelo grupo em que a licencianda participou foi à criação de um Blog, mas em comum acordo com todas as integrantes, decidiu-se pela autoria dos próprios recursos na abordagem dos conteúdos, a partir da utilização de softwares gratuitos aprendidos no decorrer da disciplina, a saber: criamos vídeos, opções de jogos, contação de história utilizando e- 
book com a apresentação em forma de vídeo, sempre buscando temas transversais e a interdisciplinaridade na forma de apresentar os conteúdos produzidos.

O objetivoera a criação de um Blog (disponível em: https://professordigital2000.blogspot.com.br) destinado à formação digital dos professores; já a criação de todo o conteúdo postado no blog, se deu pela compreensão de que para formação digital é necessário aprender com a prática e que a criação de diversos recursos digitais é possível de ser realizado. Não queríamos um Blog repositório, onde se pega tudo pronto e posta, se fosse dessa maneira seria muito comodismo, a função principal de nosso trabalho foi de construir e provar que era possível produzir tudo que publicamos.

A criação do Blog não foi fácil, pois o grupo era composto por pessoas que não sabiam utilizar os recursos, algumas não queriam sair do comodismo, queriam criar algo mais fácil. Envolver a todas na empreitada de produção de recursos e conteúdos para alimentar o Blog foi um grande desafio, pois além de ter que explorar e aprender usar diversos recursos que não conhecíamos, tivemos que lidar com os conflitos que foram gerando dentro do grupo.

Mesmo com tantos conflitos, as superações foram maiores, o resultado final do Blog foi muito bom, conseguimos ir além, cumprimos tudo o que foi planejadoe foi possível aprendermuito mais do que foi ensinado em sala de aula.

Ao final, quando apresentamos os trabalhos finais percebemos que todos os alunos construíram o Blog como recurso de TDIC para trabalhar conteúdos escolares. Mas, ninguém tentou criar algo novo, construir seus materiaise conteúdos; nós fomos o único grupo que saiu do comodismo e procurou criar o próprio conteúdo para publicare criamos não só o Blog, mas vídeos, e-books etc. que alimentaram o Blog.

\section{CONCLUSÃO}

Diante do exposto, nota-se a importância de uma disciplinaespecífica para trabalhar com TDIC na formação inicial de professores. Pois, nem todos os licenciandos tinham o total domíniode recursos de tecnologias e sequer conheciam as possibilidades para o seu uso no ensino. Outro ponto importante é saber como inserir os recursos digitais no cotidiano escolarvisando garantir uma aprendizagem contextualizada e significativa para cada aluno, respeitando suas particularidades, interesses e ritmo de aprendizagem. A esse respeito, percebemos que o papel do professor formador é fundamental, pois a mudança não deve ser nos recursos utilizados, mas na metodologia de trabalho e na clareza da intencionalidade que se tem para o ensino.

Para a integração das tecnologias o professor deve ter total domínio do conteúdo e o conhecimento de diversas mídias para tornar o ensino mais dinâmico e mais interessante para o aluno, a fim de despertar o interesse e motivá-lo para a aprendizagem.Dessa forma, o papel do professor deve ser repensado, para que deixe de ser mero transmissor e assuma o papel de mediador, estimulando a exploração e mantenham relação de cooperação mútuacom os estudantes. Nesse sentido, Hacke Negri (2010, p. 93) apontam:

Seria uma reorientação do papel do professor para a função de mediador no ensino e auxílio aos alunos para a busca e exploração dos dados existentes nas mídias.Em outras palavras, na caminhada educacional, docente e discente passam a estabelecer um diálogo constante onde a cooperação mútua passa a ser essencial e o aluno aprende a aprender, a fazer ciência, a fazer arte, enfim, a construir o conhecimento pela mediação multimidiática.

Sendo assim, é fundamental o investimentona formação inicial de professores, pois a educação deve acompanhar a evolução da sociedade e como as tecnologias estão em todos os segmentos da vida cotidiana, a educação não deve ficar de fora. Entretanto, os professores devem 
ser preparados para enfrentar essa realidade tão dinâmica, que se modifica muito rápido e se atualizar constantemente.

\section{REFERÊNCIAS}

ALMEIDA, M. E. B. de. Ensinar e aprender com tecnologias de informação e comunicação. In: . (Org.). Educação, Projetos, Tecnologia e Conhecimento. 1 ed. São Paulo: PROEM, 2001. p. $16-40$

BALADELI, A. P. D.; BARROS, M. S. F.; ALTOÉ, A. Desafios para o professor na sociedade da informação. Educar em Revista, Curitiba, Brasil, n. 45, p. 155-165, jul/set. 2012.

HACK, J. R.; NEGRI, F.. Escola e tecnologia: a capacitação docente como referencial para a mudança. Ciência e cognição, Santa Catarina, v.15, p.89- 99, abr. 2010.

PROJetO POLÍTICO PEDAGÓgICO. Curso de licenciatura em Pedagogia. Faculdade de Ciências e Tecnologia. Universidade Estadual Paulista "Júlio de Mesquita Filho". Presidente Prudente: FCT/UNESP, 2015.

RINALDI, R.P. Informática na educação: um recurso para aprendizagem significativa de portadores de necessidades especiais. Rev. de Edu. Pública, Cuiabá, v. 17, n. 35, p. 379-399, set./dez. 2008.

TUCKER, B. The FlippedClassroom. Education Next.Stanford, n. 12, v. 1, 2012. 